\title{
Study on Effect of Massage Technique based on Chaos Theory
}

\author{
Ping Feng ${ }^{1}$, Xiao-li Wang ${ }^{2}$, Chao Zhang ${ }^{3}$, Wei Sun ${ }^{4}$ and Dai-min Chen ${ }^{3}$ \\ ${ }^{1}$ College of Computer Science and Technology, Changchun University, \\ Changchun 130022, China \\ ${ }^{2}$ School of Electronic and Information Engineering, Changchun \\ University, Changchun 130022, China \\ ${ }^{3}$ Jilin Province Rehabilitation Equipment and Science andTechnology Innovation \\ Center for The Disabled, Changchun 130022, China \\ ${ }^{4}$ Graduate Department, Changchun University, Changchun 130022,China \\ 172046969@qq.com,445444726@qq.com,157075018@qq.com
}

\begin{abstract}
According to the mechanism of EMG signal, we know that the sacrificial electrical signal is with weak signal, low frequency, alternating, nonlinear and non-stationary characteristics. Nonlinear analysis includes higher order spectral analysis and fractal and chaos analysis. Chaos theory is one of the main parts of nonlinear science, and the electrical signal of the surface has a strong randomness, so we could consider the nonlinear analysis of EMG signals from the perspective of chaos. We mainly studied on the nonlinear analysis algorithm of EMG signal detailedly in this paper. Experiments show that, according to the quantitative analysis of several important parameters of rolling massage with chaos theory, we can measure objectively the action situation of related muscle groups in the operation course, then guide the professional massage students to understand the norms of operation in training of operation and help to lead their manipulation to the best power structure.
\end{abstract}

Keywords: multi-channel semg; Chaos theory; Massage technique

\section{Introduction}

In recent years, with the development of computer technology and signal processing technology, the research of bio-electrical signal has gained extensive attention, such as EMG signal and brain signal [1]. At present, with the application of bio-electrical signal, the application of EMG signal is more and more popular. For example, there is a wide range of application in the study, such as motion recognition ergonomics, motor rehabilitation, diagnosis, functional electrical stimulation and biofeedback. it has been more mature, especially in the field of ideal control signal [2]. We mainly studied on the nonlinear analysis algorithm of EMG signal detailedly in massage process.

\section{Nonlinear Index Analysis based on Chaos Theory}

According to the mechanism of EMG signal, we know that the sacrificial electrical signal is with weak signal, low frequency, alternating, nonlinear and non-stationary characteristics. With the further research of nonlinear science, people learn more deeply on the certain theory, random, quantitative change and qualitative change. Nonlinear analysis includes higher order spectral analysis and fractal and chaos analysis. Chaos theory is one of the main parts of nonlinear science, and the electrical signal of the surface has a strong randomness, so we could consider the nonlinear analysis of EMG signals from the perspective of chaos [3-4]. 
Chaos theory is used in many fields of mathematics, such as physics, engineering, electronics, biological medicine and philosophy. Chaos theory is used to study dynamic system with high sensitive initial state by influence of butterfly effect. Any tiny change of the initial state can result in different output of the chaotic system. The attractor of the invariant, such as correlation dimension, approximate entropy and Lyapunov index, is important index of chaos characteristics of characterization system [4-8]. The Lyapunov index reflects the chaotic level of the whole system in the whole state of motion. Therefore, Lyapunov index calculation is very important for the nonlinear analysis of signal.

\subsection{Lyapunov Index}

In a nonlinear dynamic system, it reflects max Lyapunov index is the key quantitative index of the system's chaotic characteristics. For any system, it is able to determine whether it is in a state of chaos when the maximum Lyapunov index of the time series of the system is calculated. Amony many methods to calculate the Lyapunov index, Wolf method and Jocobian method are widely used. and the application range of the two is not the same. G. Barana and I. Tsuda also proposed P- norm algorithm to connect Wolf method and Jocobian method, but it is very complex in numerical selection and calculation for P- norm algorithm. In 1993, M. T. Rosenstein, J. J. Collins and G. J. De proposed a calculation method of small data amount based on chaos evolution orbit of phase space, and it is a kind of improved Wolf algorithm [9].

The calculation method of small data amount is proposed in some literatures, which is the method based on the calculation of max Lyapunov index with observation sequence. By comparing with the other calculation methods of Lyapunov index, small data calculation is with less computation and relatively easy to operate; and there is a better robustness for selecting delay time of phase space, embedding dimension and the observation noise etc., With the calculation of the Lyapunov index, it can also get other important characteristics of the chaos system, such as the correlation dimension and so on [10]. We used the small data method to get the maximum Lyapunov index of each muscle group in the rolling massage process, as shown in Table 4-1.

Maximum Lyapunov index of the system is used to characterize the chaotic level of the system, which is the system sensitivity to the initial state. The maximum Lyapunov index of system is directly related to the system chaotic characteristics. If Lyapunov index is greater than 0 , the system is considered to be in the chaotic state, otherwise it does not have chaotic characteristics. The chaotic characteristics of system increases following along with the increase of maximum Lyapunov index. If the Lyapunov index reduces, the complexity of the system reduces, and the regularity of the system enhances. In Table 2-1, Lyapunov index of EMG signal in the rolling process is greater than 0, which indicates that surfacial EMG signalof the related action muscle groups may have chaotic characteristics. Maximum Lyapunov index of the massage teacher group is closer to 0 , the regularity is more obvious, and it is consistent with the required periodicity of massage technique.

\section{Table 2-1. Maximum Lyapunov Index of each Muscle Group in the Course of Operation of Massage Teacher and Student Groups}

\begin{tabular}{cccc}
\hline $\begin{array}{c}\text { Name of Muscle } \\
\text { group }\end{array}$ & $\begin{array}{c}\text { Massage } \\
\text { Teacher Group }\end{array}$ & $\begin{array}{c}\text { Student } \\
\text { Group 1 }\end{array}$ & $\begin{array}{c}\text { Student } \\
\text { Group 2 }\end{array}$ \\
\hline $\begin{array}{c}\text { Musculus triceps } \\
\text { brachii }\end{array}$ & 0.2382 & 0.6168 & 0.7810 \\
$\begin{array}{c}\text { Deltoid } \\
\text { Pectoralis major }\end{array}$ & 0.1551 & 0.0537 & 0.6132 \\
Brachioradialis & 0.2969 & 0.1574 & 0.5775 \\
\hline
\end{tabular}


The power spectrum and periodicity of EMG signal of massage technique-the power spectrum is shown in Figure 2.1. From the diagram, it can be seen the power of brachioradialis and pectoralis major muscles of teacher and student groups mainly distributed in low frequency during the process of rolling massage, and the distribution is similar, which reflects the operation flexibility. In the distribution of periodicity the power spectrum, the student group is not as good as the massage teacher group obviously in the characteristics of concentration distribution of the cycle during the process of operation.
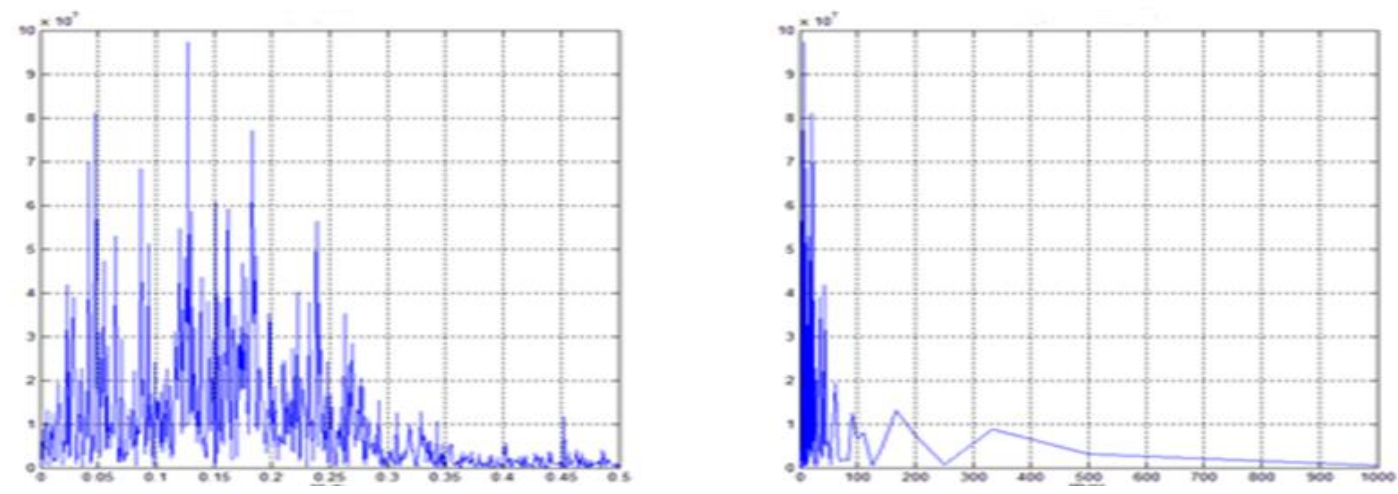

(a) The power spectrum and periodicity in the process of rolling massage of teacher group-the power spectrum
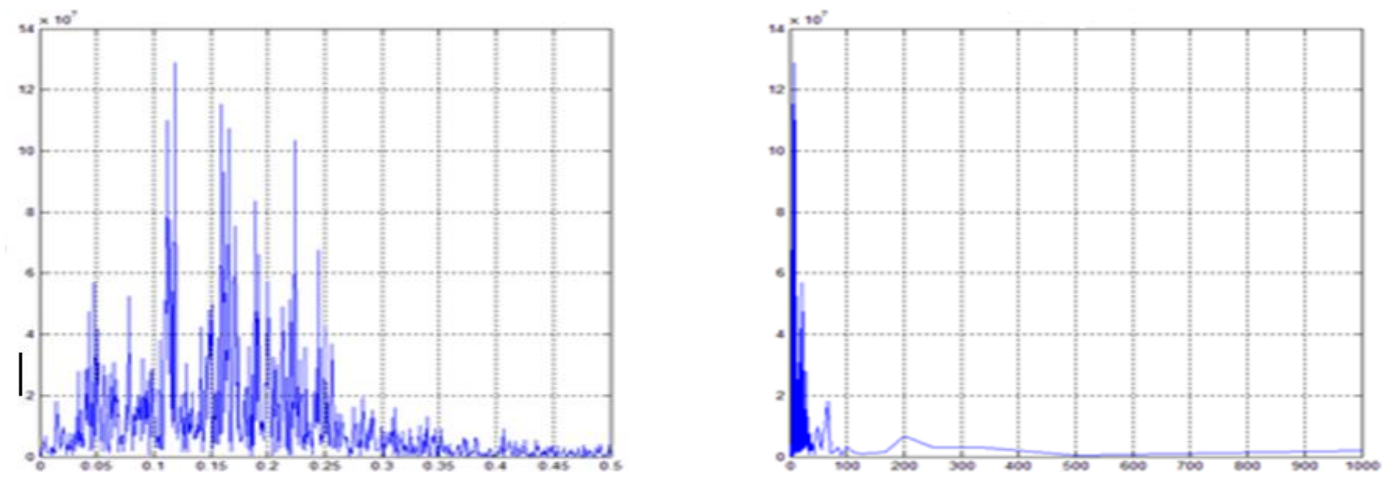

(b) The power spectrum and periodicity in the process of rolling massage of student group 1-the power spectrum
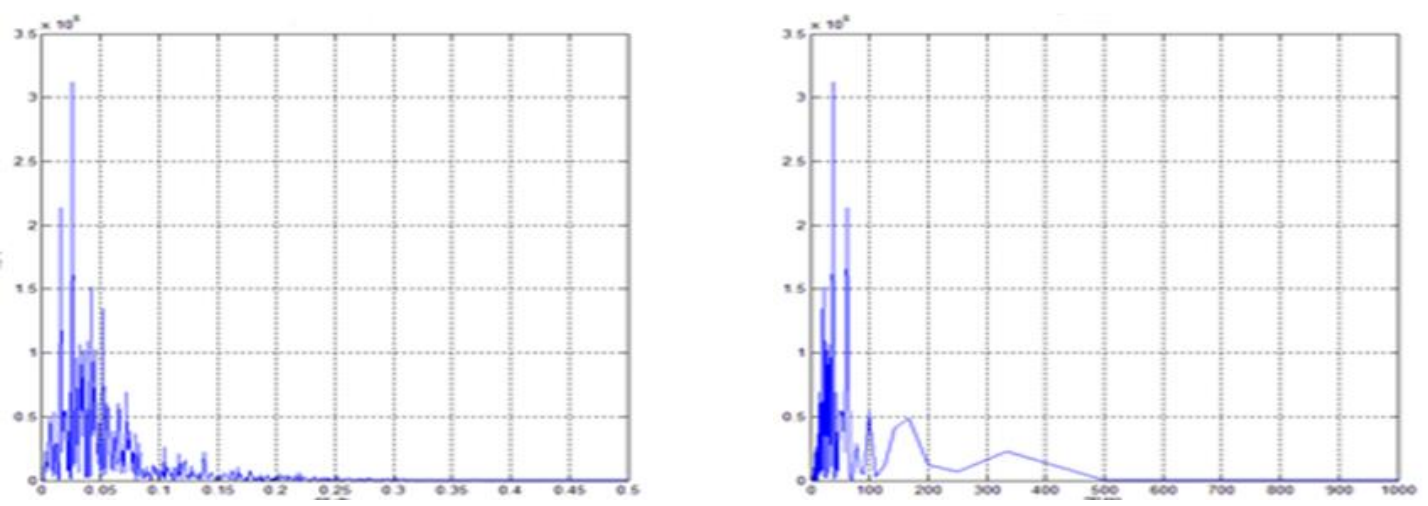

(c) The power spectrum and periodicity in the process of rolling massage of student group 2-the power spectrum

Figure 2.1. The Power Spectrum and Periodicity in the Process of Rolling Massage -the Power Spectrum 


\subsection{Correlation Dimension}

The dimension is the number of independent parameter of mathematics and the important geometric parameter in the physical space, which is the number of independent space-time coordinate [11]. In this paper, the correlation dimension is studied which is applied for small data amount. In fact, the dimension of attractor describes the phasespace structure of motion of this attractor in numerical value, and reflects the amount of information of the attractor during the movement. In a certain extent therefore, it illustrates the attractor complexity of the movement process.

In this paper, we used the classical algorithm of correlation dimension calculation, G-P algorithm proposed by Grassberger and Procaccia . Though there is the disadvantage that G-P algorithm relies on the length of time sequence, it is easy and effective to implement. Thus, the range of the application is wide. The calculation process is as follows :

(1) For chaotic time sequence $\{\mathrm{x}(\mathrm{T})\}$ different $\xi$ is chosen and $\xi$ is a small positive number, greater than 0 .

(2) Calculate the relevant correlation integral,

$C(\xi)=\lim _{N \rightarrow \infty} \frac{1}{N(N-1)} \sum_{i \neq j}^{N} \theta\left(\xi-\left|X_{i}-X_{j}\right|\right) \theta$, Heaviside unit function: $\theta(x)=\left\{\begin{array}{l}0, x \leq 0 \\ 1, x \succ 0\end{array}\right.$, observation count.

(3) Do Linear regression on the relationship of $\operatorname{lnC}(\xi)$ and $\ln \xi$, the slope is the correlation dimension $D_{2}=\lim _{\xi \rightarrow 0} \frac{\ln C(\xi)}{\ln \xi}$.

While calculating the correlation dimension, $\xi$ is usually given some specific values. While drawing $\operatorname{lnC}(\xi)-\ln \xi$ curve, the curve is divided into regions of noise, linear and saturation, in which the slope of the straight line in linear region is the correlation dimension D2. Figure 2.2, shows the curve diagram of double $\operatorname{logarithm} \ln C(\xi)-\ln \xi$ of ectopectoralis and brachioradialis muscles of rolling massage based on G-P algorithm. Table 2-2, is the correlation dimension calculated of each muscle group.
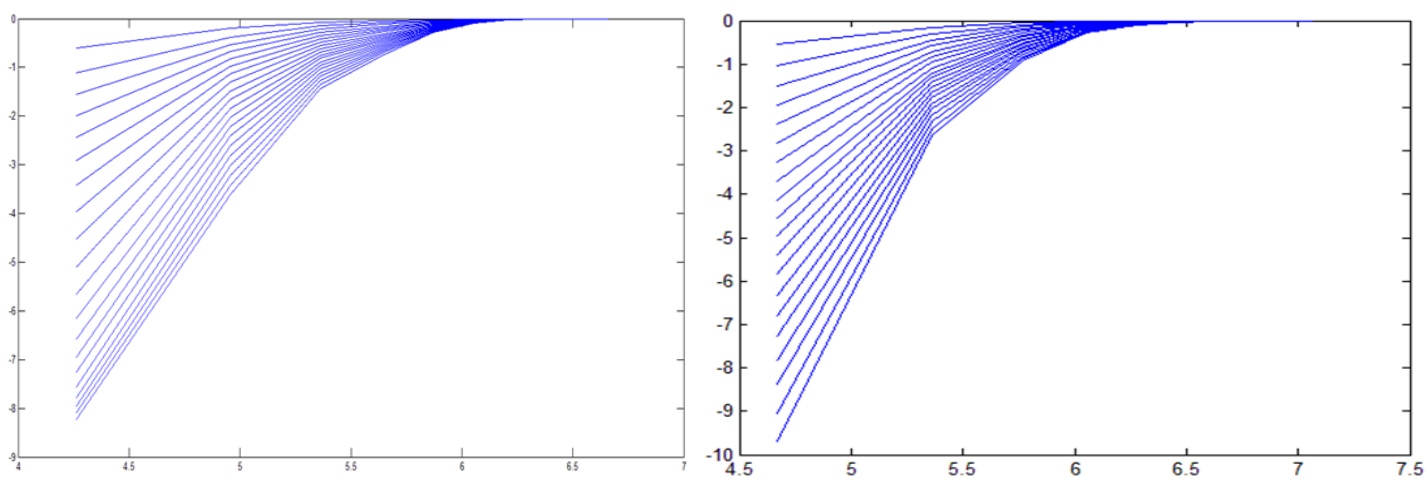

(a) The curve diagram of double logarithm $\ln C(\xi)-\ln \xi$ of ectopectoralis and brachioradialis
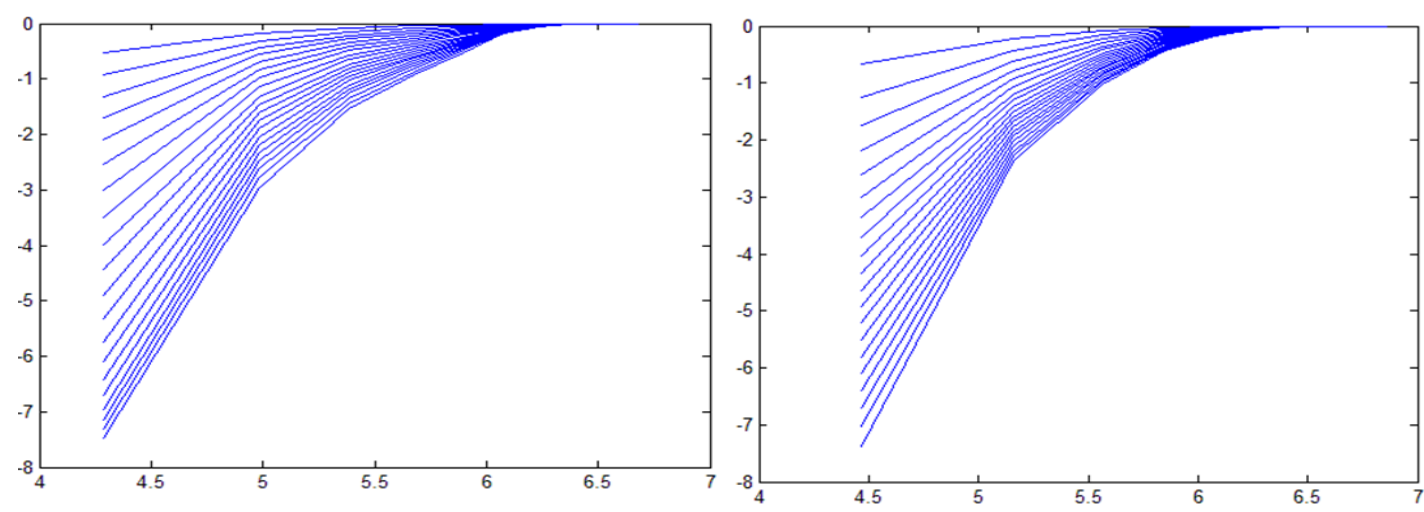
(b)The curve diagram of double logarithm $\ln C(\xi)-\ln \xi$ of ectopectoralis and brachioradialis muscles of student group one

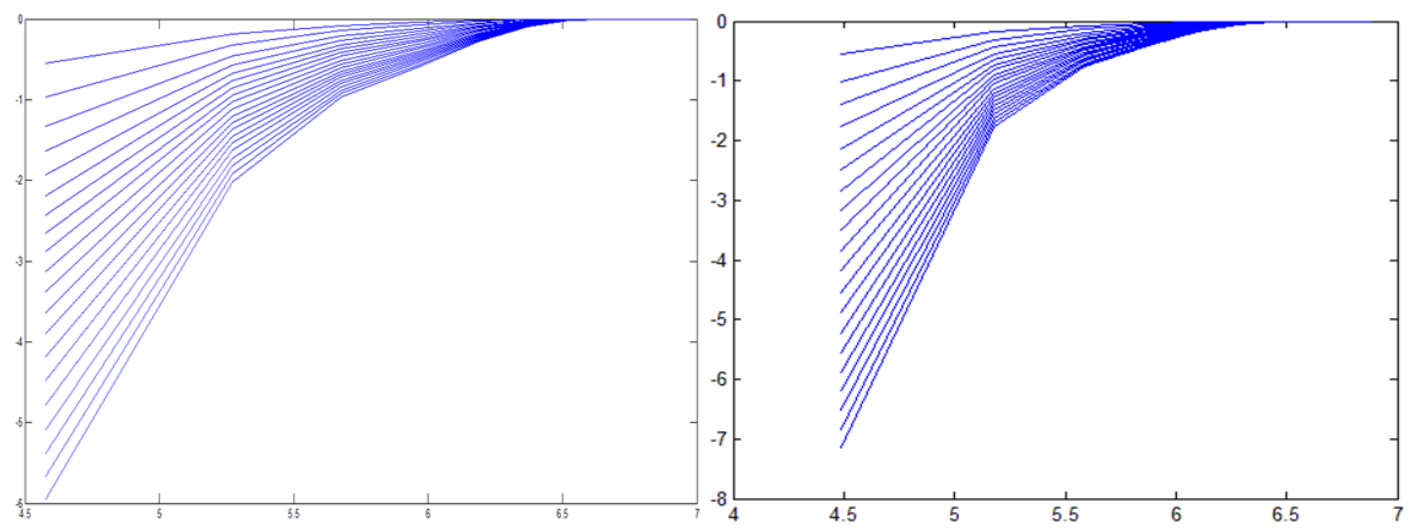

(c)the curve diagram of double logarithm $\ln C(\xi)-\ln \xi$ of ectopectoralis and brachioradialis muscles of student group two

Figure 2.2. The Curve Diagram of Double Logarithm $\ln C(\xi)-\ln \xi$ of Ectopectoralis and Brachioradialis Muscles

Table 2-2. The Correlation Dimension of Each Muscle Group of Teacher and
Student Groups in the Operation of Rolling Massage

\begin{tabular}{cccc}
\hline $\begin{array}{c}\text { Name of Muscle } \\
\text { group }\end{array}$ & $\begin{array}{c}\text { Massage } \\
\text { Teacher Group }\end{array}$ & $\begin{array}{c}\text { Student } \\
\text { Group 1 }\end{array}$ & $\begin{array}{c}\text { Student } \\
\text { Group 2 }\end{array}$ \\
\hline $\begin{array}{c}\text { Musculus triceps } \\
\text { brachii }\end{array}$ & 4.4076 & 5.4176 & 3.5416 \\
Deltoid & 5.1717 & 2.5170 & 4.5265 \\
Pectoralis major & 3.0888 & 2.7763 & 2.1326 \\
Brachioradialis & 3.2993 & 2.6022 & 2.4169
\end{tabular}

According to the definition of correlation dimension, it generally believes that if the correlation dimension is small, it means the complexity and stability of motion system in the phase space is lower; if the correlation dimension is fraction, it indicates that system motion may be the irregular chaotic motion. Therefore, the correlation dimension can be used to describe the stability of surface EMG signal. Firstly, from the table we can see that the correlation dimension is fraction and has fractal dimension characteristics. Once again, it shows that the rolling method probably belong to chaotic motion. Secondly, the correlation dimension of teacher group was greater than student group one and two, which shows that the students in the group massage are lack of stability during operation, and need to strengthen it in the future training.

\subsection{Approximate Entropy}

Approximate entropy (ApEn) is proposed by Pincus, to measure the complexity of chaotic phenomena in the early 1990s [12-13]. It describes a rule of complexity and quantitative statistics of dynamic system in the motion of phase space. Approximate entropy is applied in time sequence to distinguish the various state processes of system by using the marginal probability distribution, and it is not reconstructed attractor [14-15]. In the practical engineering application, approximate entropy has the characteristics as follows:

(1) the required amount of data to get relatively stable statistical value by estimating approximate entropy is relatively less, generally in 100 5000 point, and we choose 1000 point generally;

(2) the ability to deal with anti interference and anti noise is strong. In particular, it has a relatively good bearing capacity to the accidental transient strong interference. 
(3) approximate entropy is appropriate for random, deterministic and mixed signals. As calculating approximate entropy of mixed signal, considering of the different proportions of random and determine signals, the approximate entropy is not the same. Therefore, calculating the approximate entropy is very useful for the biological signals, which are of mixed signals.

(4) Approximate entropy is applied to describe the possibility of new changes of signals in the state of motion, from the complexity of time sequence measurement generally. And approximate entropy increases as the ratio of the possibility of new changes of signals and the complexity of time sequence increase.

In theory, approximate entropy reflects the motion complexity of dynamical system in phase space, and the system complexity and approximate entropy is proportional, as a non negative. Approximate entropy expresses the irregular signals in the dynamic system generally, the complexity of the time sequence decides approximate entropy value, and both are proportional. From the statistical theory, a smaller amount of data can estimate stable value of approximate entropy.

According Pincus theory, we can get approximate entropy and complexity of the massage teacher and the student groups in rolling process, shown in Tables 2-3, and 2-4. Approximate entropy can describe the complexity of surface EMG signal, and the complexity is proportional to approximate entropy. The greater approximate entropy is, the greater the randomness and complexity of the rolling process are. On the contrary, if approximate entropy is smaller, the change of the frequency components in the rolling process is smaller, which means that the operation of massage tends to be more regular. From tables, it can be known that the rolling massage of teacher and student groups has a strong periodicity.

\section{Table 2-3. The Values of Approximate Entropy of Each Muscle Group in the} Operation Process of Rolling Massage

\begin{tabular}{cccc}
\hline $\begin{array}{c}\text { Name of Muscle } \\
\text { group }\end{array}$ & $\begin{array}{c}\text { Massage } \\
\text { Teacher Group }\end{array}$ & $\begin{array}{c}\text { Student } \\
\text { Group 1 }\end{array}$ & $\begin{array}{c}\text { Student } \\
\text { Group 2 }\end{array}$ \\
\hline $\begin{array}{c}\text { Musculus triceps } \\
\text { brachii }\end{array}$ & 1.1780 & 1.1988 & 1.2624 \\
Deltoid & 1.0222 & 1.0518 & 1.1138 \\
Pectoralis major & 0.9160 & 0.9196 & 0.9247 \\
Brachioradiali & 1.1256 & 1.1330 & 1.2015 \\
\hline
\end{tabular}

Table 2-4. The Values of Complexity of Each Muscle Group in the Operation Process of Rolling Massage

\begin{tabular}{cccc}
\hline $\begin{array}{c}\text { Name of Muscle } \\
\text { group }\end{array}$ & $\begin{array}{c}\text { Massage } \\
\text { Teacher Group }\end{array}$ & $\begin{array}{c}\text { Student } \\
\text { Group 1 }\end{array}$ & $\begin{array}{c}\text { Student } \\
\text { Group 2 }\end{array}$ \\
\hline $\begin{array}{c}\text { Musculus triceps } \\
\text { brachii }\end{array}$ & 0.8172 & 0.8870 & 0.8969 \\
Deltoid & 0.8277 & 0.8252 & 0.8471 \\
Pectoralis major & 0.7175 & 0.7225 & 0.7375 \\
Brachioradialis & 0.9267 & 0.9375 & 0.9667 \\
\hline
\end{tabular}

\section{Result and Analysis}

According to statistical analysis, we took massage teacher group as the evaluation criteria of work standards of massage. If the parameter index of the student's massage technique within the certain threshold range of corresponding massage group of teachers, we think the student practice is correct and effective. EMG signal analysis on massage, based on the nonlinear chaos theory, showed that: according to the comparative analysis of quantitative indicators between the massage groups of teachers and students, the characteristic parameters of chaos theory, including the largest Lyapunov index, 
correlation dimension and approximate entropy, had different variation. Parameter values can show the difference in the level of operation clearly.

\section{Conclusions}

The quantitative result analysis of chaos theory calculation is consistent with the traditional method. According to the quantitative analysis of several important parameters of rolling massage with chaos theory, we can measure objectively the action situation of related muscle groups in the operation course, then guide the professional massage students to understand the norms of operation in training of operation and help to lead their manipulation to the best power structure.

\section{References}

[1] N. P. Reddy and V. Gupta, "Toward direct biocontrol using surface EMG signals: Control of finger and wirst joint models", Medical Engineering \& Physics, (2013), pp. 398-403.

[2] N. Masud and K. Aihara, "Cryptosystems W ith Discretized Chaotic Maps", IEEE Trans Circuitand Systems, vol. 49, no. I, (2012), pp. 28- 40.

[3] J. C. Yen and J. I. Guo, "A new chaotic key—based design for image encryption and decryption", IEEE InternationalSymposium on CircuitsandSystems, vol. IV, (2000), pp. 49- 52.

[4] J. C. Yen and J. I. Guo, "Efficienthierarchicalchaoticima geencryption alogorithm andits VLSIrealis Tion",1EE proc. visImageSiglIal Process, vol. 147, no. 2, (2000), pp. 167- 175.

[5] M. Khezri and M. Jahed, "An exploratory study to design a novel hand movement identification system", Computers in Biology andMedicine, vol. 39, (2012), pp. 433-442.

[6] C. Xiang, L. Qiang, Y. Ji-Hai, V. Lantz and W. K. Qiao, "Test-retest repeatability of Surface Electromyography Measurement for Hand Gesture",The 2nd International Conference on Bioinformatics and Biomedical Engingeering, (2008), pp. 1923-1926.

[7] J. Fridrich, "Imageencryptionbasde onchaoticam ps", EI EE, (1997), pp.·1105- 1110.

[8] J. T. Yan, "The teaching material of new century higher TCM colleges - science of Chinese massage", Beijing: China Chinese medicine press, no. 85, (2004).

[9] Y. Zhiguo, "The Reduction and Classification of Nonlinear Features for Semg Signals Based on Rough Set and Support Vector Machines", College of Life Science and Biotechnology Shanghai Jiao Tong University, (In Chinese), (2008).

[10] L. Qiang, L. Bo and Y. Hai-ji, "Noise reduction of surface electr-omyography signal using spectrum interpolation and empirical modedecomposition", Application Research of Computers, vol. 27, no. 9, (2010), pp. 3326.

[11] X. L. YANG and Z. Z. LUO, "The algorithm of OGWE and its application on surface electro Myography”, Journal of Huazhong Univ. of Sci. \& Tech.(Natural Science Edition), vol. 39, no. 2, (2013), pp. 411-413.

[12] J. Strik, R. Lousberg and E. Cheriex,"One year cumulative incidence of depression follo wing myocardial infarction and impact on cardiac outcome", J. Psychosom Res, vol. 56, (2004), pp. 59 -66.

[13] M. Kaki, M. Hassan and Q. Li, "Coronary Artery Disease and Depression: Patients With More Depressive Symptoms Have Lower Cardiovascular Reactivity During Laboratory-Induced Mental Stress", Psychosomatic Medicine, vol. 69, (2007), pp. 521-528.

[14] J. Hofslein, N. Graham and J. Pipher, "NTRUSign : digitalsigna-tures using the NTRU tice", Springer-Verlag, (2003), pp. 122-140.

[15] D. L. Hanke-on and J. A. Hernaadez, "Menacessotfware implementation of ellipticcryptography overbinary ifelds", Proceedings of the 2nd International Workshop On Cryptographic Hardware and Embedded System s.London.UK, (2000), pp. 1-24. 
International Journal of $u-$ and e- Service, Science and Technology Vol. 9, No. 12 (2016) 